\title{
The Welfare Comparison of Ad-Valorem Tax and Specific Tax with Both Quality and Quantity Choice of a Consumer
}

\author{
Takuya Obara $^{1 *}$, Shuichi Tsugawa ${ }^{2}$ \\ ${ }^{1}$ Graduate School of Economics, Hitotsubashi University, Tokyo, Japan \\ ${ }^{2}$ Graduate School of Economics, Toulouse School of Economics, Toulouse, France \\ Email: *ed142003@g.hit-u.ac.jp
}

How to cite this paper: Obara, T. and Tsugawa, S. (2017) The Welfare Comparison of Ad-Valorem Tax and Specific Tax with Both Quality and Quantity Choice of a Consumer. Theoretical Economics Letters, 7, 1797-1813.

https://doi.org/10.4236/tel.2017.76122

Received: September 16, 2017

Accepted: October 23, 2017

Published: October 26, 2017

Copyright $\odot 2017$ by authors and Scientific Research Publishing Inc. This work is licensed under the Creative Commons Attribution International License (CC BY 4.0).

http://creativecommons.org/licenses/by/4.0/

\begin{abstract}
This paper compares ad-valorem and specific taxation in models where a representative consumer with an exogenous income has both a quality and a quantity choice under perfect competition. In the setting, while ad-valorem tax causes income effect only, specific tax causes both income effect and substitution effect. Therefore, ad-valorem tax decreases consumer demand for both quality and quantity; on the other hand, specific tax decreases consumer demand for quantity. However, the sign of consumer demand for quality is ambiguous and is determined by the curvature of marginal utility on quantity. Additionally, using a constant elasticity of substitution (CES) utility function and a linear price function, we show that ad-valorem tax is superior to specific tax except for the Leontief preference under which the two forms of commodity taxes generate the same tax revenue. The substitution effect caused by specific tax disappears if the elasticity of substitution converges to zero.
\end{abstract}

\section{Keywords}

Quality Choice of a Consumer, Specific Tax, Ad-Valorem Tax, Substitution Effect, Welfare Comparison

\section{Introduction}

In the field of public finance, there are many studies that compare social welfare under ad-valorem and specific taxation. The seminal contribution of [1] examines the impact of two different tax structures on welfare keeping the same tax revenue under a monopoly market. The author shows that an ad-valorem tax is superior to a specific tax. Some works that approach the comparison under 
imperfect competition support the conclusion (see [2]-[7]).

However, these studies ignore the impact of the tax structure on the product quality selected by firms. If both forms of taxation affect the quality, wholly specific taxation can be optimal under perfect competition (see [8] [9] and [10]). To cover the cost of improving quality, the increment in tax revenue under specific tax is less than the increment under ad-valorem tax because of the "multiplier effect."

Our aim in this paper is to compare the two forms of commodity taxation in terms of welfare when the consumer has both a quantity and a quality choice under perfect competition. Contrary to the aforementioned literature, we assume that a representative consumer, not firms, determines product quality provided under a perfect competition market. In other words, a given good/service is available to the consumer at different quality levels. In the setting, there are two margins of choice for the consumer: quality choice and quantity choice. At the quality choice margin, the consumer chooses a degree of excellence of the good/service. At the quantity choice margin, the consumer determines the amount of the good/service given the quality. Imagine a situation in which the consumer can choose not only the number of hours that his parents are at the elderly care center but also the quality of the facility. Both quality and quantity affect utility. In particular, quality choice brings a positive impact on the unit price because it is quite natural that the higher quality he chooses, the more he pays the unit price. The basic structure of our model is close to the [11] model. The authors study optimal ad-valorem and specific taxation as well as nonlinear income taxation, but our setting and concern differ from [11]. The study investigates the two forms of commodity taxation under nonlinear labor income taxes when individuals have different productivity, and there is asymmetric information between the policymaker and taxpayers with respect to individuals' productivity. Both consumption taxes play a crucial role in relaxing incentive constraints, thus, such taxes are necessary to implement the second-best allocation, which contradicts the canonical results provided by [12] Contrary to their paper, we allow the government to levy taxes on such consumption only and assume homogeneous individuals. That is, there is no asymmetric information. Instead of studying the linkage between commodity taxes and relaxing incentive constraints on income taxes, we present the welfare comparison between an ad-valorem and a specific tax in the sense of taxpayer's utility and the response in the change of each tax rate using the comparative statics analysis. Additionally, [13] is related to our paper and studies consumer behavior when the consumer can choose both quality and quantity; however, the cited paper does not study tax incidence.

We find that specific taxation distorts the consumer's choice between quantity and quality, whereas introducing ad-valorem taxation does not affect the choice. In other words, while the marginal rate of substitution between a quantity and a quality includes the tax rate under specific tax, the corresponding marginal rate 
of substitution does not include the tax rate under an ad-valorem tax. The unit tax rate makes the consumer reluctant to purchase more, whereas he is willing to improve the quality to compensate for lost utility. Subsequently, assuming that a price function is linear and individual preference is expressed by the constant elasticity of the substitution (CES) utility function, we analytically show that an ad-valorem tax is superior to a specific tax in the presence of a substitution effect, if any. The difference in indirect utilities between ad-valorem tax and specific tax decreases as the elasticity of substitution decreases; the two forms of taxation are equivalent when consumers have Leontief preference. The findings imply that the substitution effect under a specific tax plays an important role in ad-valorem tax dominating a specific tax in terms of consumer welfare.

The next section describes our abstract model with assumptions guaranteeing the existence of an optimal solution for a representative consumer. Section 3 provides a comparative statics analysis under these two taxes. Using CES utility and linear price function, we study welfare comparison with numerical simulation as an example in Section 4. We show most of our complex calculations to derive our results in Appendices. Section 5 concludes.

\section{The Model}

In this model, there is a single representative consumer with initial wealth $I$. He consumes only one type of good and can choose both quantity and quality. Let $y \in \mathbb{R}_{++}$be a quantity and $\theta \in \mathbb{R}_{++}$be a quality. The price for unit consumption is determined by quality via a strictly increasing and differentiable function $p(\theta)$. The consumer derives utility from quantity and quality, which is defined by $v(y, \theta)$. To guarantee an interior solution with respect to each input, we assume that $v$ is twice differentiable, strictly increasing, and strictly concave in $(y, \theta)$.

The government can put tax on either the unit price $p(\theta)$ or the quantity $y$. If the consumer adopts an ad-valorem tax $t^{a}$, the budget constraint must be:

$$
\left(1+t^{a}\right) p(\theta) y \leq I,
$$

while if the consumer chooses a specific tax $t^{s}$, the budget constraint must become

$$
\left(p(\theta)+t^{s}\right) y \leq I
$$

The taxpayers maximize their own utility with respect to quantity $y$ and quality $\theta$ given the budget constraint. From the first order conditions, we can derive the following ad-valorem and specific tax wedge:

$$
\begin{aligned}
& \frac{v_{y}\left(y^{a}, \theta^{a}\right)}{v_{\theta}\left(y^{a}, \theta^{a}\right)}=\frac{p\left(\theta^{a}\right)}{p^{\prime}\left(\theta^{a}\right) y^{a}} \\
& \frac{v_{y}\left(y^{s}, \theta^{s}\right)}{v_{\theta}\left(y^{s}, \theta^{s}\right)}=\frac{p\left(\theta^{s}\right)+t^{s}}{p^{\prime}\left(\theta^{s}\right) y^{s}}
\end{aligned}
$$


where $v_{k}$ denotes the derivative of $v$ with respect to $k=y, \theta$, the subscript $a$ the choice of an ad-valorem tax, and $s$ is the choice of a specific tax. Given initial wealth $I$, tax rate $t$, and tax scheme $i=s, a$, their quantity choice function, quality choice function, and indirect utility function are defined as follows: $y\left(t^{i}, I\right), \theta\left(t^{i}, I\right)$, and $V\left(t^{i}, I\right)$.

When the government employs an ad-valorem tax, the budget constraint faced by the consumer is:

$$
t^{a} p\left(\theta^{a}\right) y^{a} \geq R
$$

where $R$ is an exogenous amount of public expenditure. On the other hand, if the consumer imposes a specific tax, the budget constraint is:

$$
t^{s} y^{s} \geq R
$$

\section{Comparative Statics of $(y, \theta)$ on Tax Rate $t$ under Ad-Valorem Tax and Specific Tax}

How do an ad-valorem tax and a specific tax affect the consumer's demand for quantity $y$ and quality $\theta$ ? In this chapter, we study the sensitivity of their choice $(y, \theta)$ in response to each tax rate increase.

Let $|K|$ and $|M|$ be the determinants of a border Hessian matrix on the optimization problem under ad-valorem tax and specific tax. By the comparative statics of $y$ and $\theta$ under ad-valorem tax, these derivatives are:

$$
\begin{gathered}
\frac{\partial \theta}{\partial t^{a}}=\frac{1}{|K|} \frac{v_{\theta} v_{y} p(\theta)}{\gamma^{a}}\left(1-\rho-\varepsilon_{y}^{v_{\theta}}\right) \\
\frac{\partial y}{\partial t^{a}}=\frac{1}{|K|} \frac{v_{\theta} p(\theta) y}{\gamma^{a}}\left(\frac{v_{\theta}}{y}\left(1-\varepsilon_{y}^{v_{\theta}}\right)+v_{y}\left\{\frac{v_{\theta \theta}}{v_{\theta}}-\frac{p^{\prime \prime}(\theta)}{p^{\prime}(\theta)}\right\}\right)
\end{gathered}
$$

where $\gamma^{a}$ is the Lagrangian multiplier under ad-valorem tax, $\rho \equiv-\frac{v_{y y} y}{v_{y}}$ is the curvature of marginal utility on quantity $y, v_{\theta y}$ is the cross-derivative of $v$, and $\varepsilon_{y}^{v_{\theta}} \equiv \frac{v_{\theta y}}{v_{\theta}} y$ is the demand elasticity of $v_{\theta}$. We would guarantee the second-order condition for this utility maximization under ad-valorem tax. Thus, we impose the following assumptions: $\varepsilon_{y}^{v_{\theta}} \geq 1$ and $p^{\prime \prime}(\theta) \geq 0$ (see Appendix A).

From Equation (7) and Equation (8), both demands for quality $\theta$ and quantity $y$ decrease as ad-valorem tax increases; that is, $\frac{\partial \theta}{\partial t^{a}}\left(t^{a}, I^{a}\right)<0$ and $\frac{\partial y}{\partial t^{a}}\left(t^{a}, I^{a}\right)<0$ if the second-order condition is satisfied. The intuition is that as the ad-valorem tax increases, the consumer's disposable income decreases by $\frac{t^{a}}{1+t^{a}}$ percent. On the other hand, the marginal rate of substitution between quantity and quality is the same as that without imposing the tax. Hence, 
decreasing disposable income decreases the consumer's demands for both quantity and quality due to the income effect.

On the other hand, the comparative statics results under specific tax are:

$$
\begin{gathered}
\frac{\partial \theta}{\partial t^{s}}=\frac{1}{|M|} \frac{v_{\theta} v_{y}}{\gamma^{s}}\left(2-\rho-\varepsilon_{y}^{v_{\theta}}\right) \\
\frac{\partial y}{\partial t^{s}}=\frac{1}{|M|}\left(-\frac{v_{\theta} v_{\theta y} y}{\gamma^{s}}+\frac{v_{y} v_{\theta} y}{\gamma^{s}}\left(\frac{v_{\theta \theta}}{v_{\theta}}-\frac{p^{\prime \prime}(\theta)}{p^{\prime}(\theta)}\right)\right)
\end{gathered}
$$

where $\gamma^{s}$ is the Lagrangian multiplier under specific tax. Similar to the ad-valorem tax case, it is assumed that $\varepsilon_{y}^{v_{\theta}} \geq 1$ and $p^{\prime \prime}(\theta) \geq 0$ so that the second-order condition holds (see Appendix A).

From Equation (9) and Equation (10), while $\frac{\partial y}{\partial t^{s}}\left(t^{s}, I^{s}\right)$ is negative, the sign of $\frac{\partial \theta}{\partial t^{s}}\left(t^{s}, I^{s}\right)$ is ambiguous. Put differently, employing a specific tax induces the consumer to reduce his demand for quantity but perhaps to select better quality as opposed to that of the ad-valorem tax case. This is because the income effect and the substitution effect occur as shown in Equation (4). From Equation (9), whether the quality is improved depends on $\rho$, which indicates the extent to which the consumer wants to maintain the quantity. If $\rho$ is larger (smaller) than 1, the bracket in Equation (9) may be negative (positive), so $\frac{\partial \theta}{\partial t^{s}}\left(t^{s}, I^{s}\right)$ is negative (positive).

The intuition is that when the elasticity of the consumer's marginal utility on quantity is greater than 1 , the consumer is not willing to decrease quantity and debases the quality to cover his expenditure. In contrast, if $\rho$ is sufficiently small, the consumer does not hesitate to decrease the quantity, whereas the consumer upgrades the quality to compensate for the utility loss caused by the decrease in quantity. Thus, whether the income effect dominates the substitution effect depends on $\rho$.

We summarize the above arguments in the following proposition.

Proposition 1. Assume that each sufficient condition for the representative consumer's optimization problem is satisfied. Then,

a) Under an ad-valorem tax, both $\frac{\partial \theta}{\partial t^{a}}\left(t^{a}, I^{a}\right)$ and $\frac{\partial y}{\partial t^{a}}\left(t^{a}, I^{a}\right)$ are negative, that is, both demand for quality $\theta$ and quantity $y$ decrease in response to the tax increase.

b) Under specific tax, $\frac{\partial y}{\partial t^{s}}\left(t^{s}, I^{s}\right)$ is negative, which means that the demand decreases when the tax rate increases while the sign of $\frac{\partial \theta}{\partial t^{s}}\left(t^{s}, I^{s}\right)$ is determined by $\rho$. Particularly, the consumer's demand for quality decreases if $\rho>1$.

Here, we present a special case in which the second-order condition is 
satisfied, and the following example is also used in the next section. We assume that the price function is linear $p(\theta)=a \theta$ where $a>0$ and individuals' preference is the constant elasticity of the substitution (CES) utility function expressed by $v(y, \theta)=\left(\alpha y^{-\sigma}+\beta \theta^{-\sigma}\right)^{-\frac{1}{\sigma}}$, where $\alpha>0, \beta>0, \alpha+\beta=1$, and $\sigma$ are measures of complementarity assuming that $\sigma \geq 1 \cdot \frac{1}{1+\sigma}$ is the elasticity of substitution. It is obvious that $p^{\prime \prime}(\theta) \geq 0$ is satisfied. Additionally, if $\sigma \geq 1, \varepsilon_{y}^{v_{\theta}} \geq 1$ under both ad-valorem tax and specific tax. Therefore, the results of proposition 1 hold in the environment. Moreover, we demonstrate that consumers retain quality or select lower quality under specific tax, that is, $\frac{\partial \theta}{\partial t^{s}} \leq 0$. The proofs are given in Appendix B, and the results are summarized in the next corollary.

Corollary 1 . Suppose that a representative consumer has CES utility function $v(y, \theta)=\left(\alpha y^{-\sigma}+\beta \theta^{-\sigma}\right)^{-\frac{1}{\sigma}}$, where $\alpha>0, \quad \beta>0, \alpha+\beta=1$, and faces a linear price function $p(\theta)=a \theta$. Under both ad-valorem tax and specific tax, the consumer demands for both quality and quantity decrease in response to the tax rate increase.

\section{Welfare Comparison}

This section examines whether the government should adopt an ad-valorem or a specific tax under the same tax revenue. For the remainder of the manuscript, we use the following environment that was used in the previous special case: the price function is $p(\theta)=a \theta$ where $a>0$, and the individual's preference is the CES utility function given by $v(y, \theta)=\left(\alpha y^{-\sigma}+\beta \theta^{-\sigma}\right)^{-\frac{1}{\sigma}}$ where $\alpha>0$, $\beta>0, \alpha+\beta=1$ and $\sigma \geq 1$. As mentioned in section 3 , the assumptions on the price function and the utility function ensure the second-order conditions for the maximization problem. Additionally, the elasticity of substitution $\frac{1}{1+\sigma}$ is between 0 and $\frac{1}{2} \cdot \sigma$ is a component of the elasticity of substitution and can be interpreted as the degree of complementarity. In the setting, we can state the following.

Proposition 2. Assume that the price function is linear and the individual's preference is the CES utility function, that is, $p(\theta)=a \theta$ where $a>0$ and $v(y, \theta)=\left(\alpha y^{-\sigma}+\beta \theta^{-\sigma}\right)^{-\frac{1}{\sigma}}$ where $\alpha>0, \beta>0, \alpha+\beta=1$, and $\sigma \geq 1$. If the tax revenue remains the same under ad-valorem and specific tax,

a) ad-valorem tax is superior to specific tax in terms of the consumer's welfare except for the elasticity of substitution $\frac{1}{1+\sigma}=0$;

b) the difference in welfare, that is, $v\left(y^{a}, \theta^{a}\right)-v\left(y^{s}, \theta^{s}\right)$ decreases as $\sigma$ increases, or the elasticity of substitution decreases; 
c) ad-valorem tax and specific tax are indifferent in terms of the welfare when $\sigma=\infty$, that is, the utility function is a Leontief preference $v(y, \theta)=\min \{y, \theta\}$.

This is shown in Appendix C. The result is intuitive. As shown by Equation (3) and Equation (4), the marginal rate of substitution between quantity and quality includes the tax rate under specific tax; the corresponding marginal rate of substitution does not include the tax rate under an ad-valorem tax. In other words, the income effect only changes consumption choice under an ad-valorem tax (Figure 1), whereas the substitution effect as well as the income effect distort consumption choice under specific tax (Figure 2). This implies that if a substitution effect exists, specific taxation generates welfare losses since it distorts the individual's behavior relative to the case without any tax policy. Therefore, an ad-valorem tax is superior to a specific tax. The findings that an ad-valorem tax is superior to a specific tax does not depend on the specification of the utility function and the price function and the assumption that the government can impose either an ad-valorem or a specific tax. Indeed, we show the statement without specifying these functions when the government can employ both an ad-valorem and a specific tax simultaneously (see Appendix D).

Additionally, the increase in $\sigma$ implies that the substitution effect becomes smaller. In other words, welfare losses caused by specific tax diminishes. Consequently, the welfare difference decreases and, particularly, when the utility

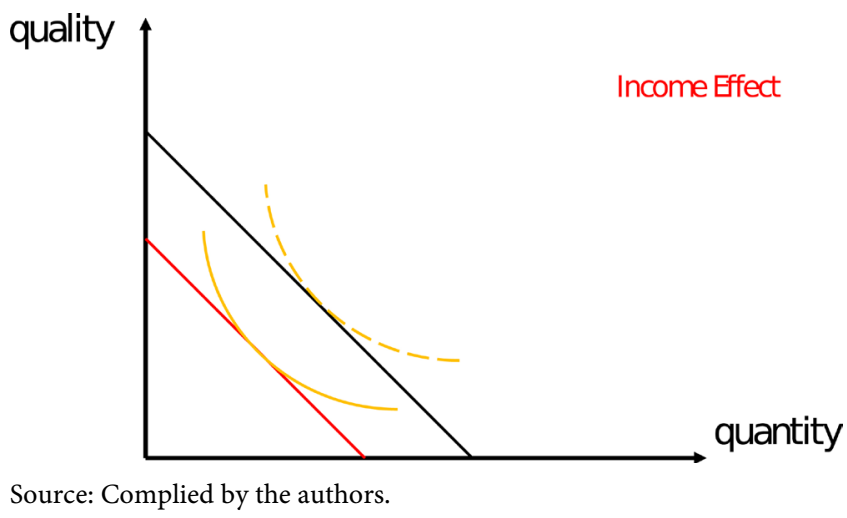

Figure 1. The effect of ad-valorem tax on a consumer's choice.

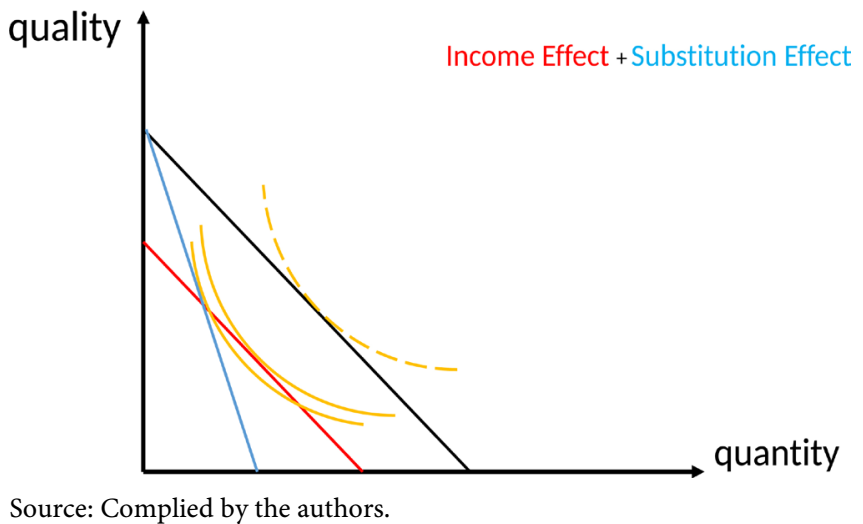

Figure 2. The effect of specific tax on a consumer's choice. 


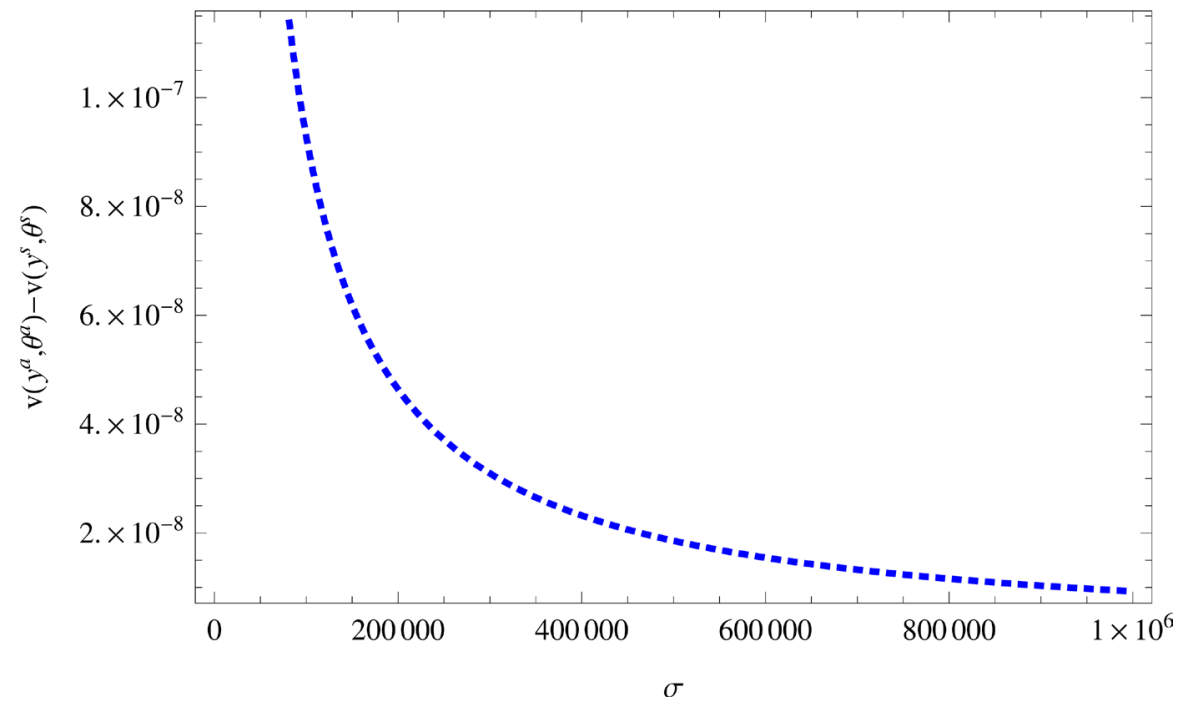

Source: Complied by the authors.

Figure 3. Simulations of $v\left(y^{a}, \theta^{a}\right)-v\left(y^{s}, \theta^{s}\right)$ with respect to $\sigma$.

function is Leontief preference, it is possible for the policymaker to achieve the same utility level via a specific tax as an ad-valorem tax. This is because there is no substitution effect under Leontief preference, which leads to the assumption that the consumption decision toward changing the tax rate is affected only by the income effect regardless of an ad-valorem tax and a specific tax. Our conclusion is illustrated in Figure 3 for $R=1, I=6, a=1, \alpha=\beta=0.5$ and $\sigma \in[1, \infty)$.

Although Figure 1 and Figure 2 provide an illustrative explanation, these budget lines are not correct because the consumer's budget set is partially determined by a linear price function; therefore, each budget line should not be straight. However, it is sufficient to explain the mechanism of our result if the curvature of the budget line is smaller than that of the consumer's utility indifference curve, which is the condition to maximize utilities.

\section{Concluding Remarks}

This paper compares ad-valorem tax and specific tax from the perspective of a representative consumer's welfare when the consumer has both a quantity and a quality choice. Contrary to most papers investigating such a comparison of social welfare under imperfect competition, we allow for quality choice as well as a competitive environment. Using a linear price function for quality and CES utility function, we identify that the substitution effect distorts the consumer's optimal choice under specific tax, which leads to the consequence that ad-valorem tax dominates the consumer's choice in the sense of the consumer's utility. On the other hand, since the substitution effect vanishes under Leontief preferences, the two forms of tax are equivalent. Our main result is different from that of previous studies, which show that specific tax can be superior to ad-valorem tax for social welfare under quality choice by production sector, as in 
[8] [9] and [10]. These papers argue that the "multiplier effect" imposes excess burden on improving product quality. Therefore, specific tax can be superior to ad-valorem tax under firms' quality choices, but the representative consumer in our model can choose quality, so ad-valorem tax is like a lump-sum tax on initial wealth. Thus, only income effect distorts the consumer's decision. Roughly speaking, this explains why ad-valorem tax is superior to specific tax in our model unless the elasticity of substitution equals 0 .

Although our model is simple in the sense that consumers focus on one taxable good, as the first step, we have priority over unveiling the interaction between preference and two tax schemes. Additionally, the result can be applied to a case in which the consumer faces liquidity constraints. For instance, in a housing choice, the consumer selects the location and scale, and the government often collects taxes from such consumption. Our result suggests that the government should levy taxes on the unit land price if consumers have substitution between location and scale. Consequently, this study has implications for the understanding of the effect of two forms of commodity tax on consumer's quality choice.

The unsolved question in our paper is whether an ad-valorem tax is superior to a specific tax for many taxable goods. In this situation, the government faces an additional problem, which is the choice between a uniform or differentiated commodity tax from the standpoint of efficiency. If the government employs a uniform tax on all goods, we conjecture that our main conclusion holds because an ad-valorem tax still acts as a lump-sum tax while a specific tax distorts the consumer's choice between the quality and quantity of taxable goods. However, if the government employs differentiated indirect taxes, an ad-valorem tax distorts the consumer's choice compared to the model under one taxable good, which means that wholly ad-valorem tax may not be optimal. [14] is an important study that solves the question since the paper shows that a uniform tax is desirable under an exogenous income. If the findings hold even under the situation in which consumers can choose quantity and quality, wholly ad-valorem tax would be desirable even under many taxable goods if income is given as it is in our setting. Moreover, to clarify whether the desirability of an ad-valorem tax crucially depends on the assumption of an exogenous income, we will extend the model by allowing consumers to choose the amount of labor supply. This theme is left for future research.

\section{Acknowledgements}

We would like to thank our supervisors Helmuth Cremer, Jean-Marie Lozachmeur, and Motohiro Sato for invaluable comments and discussions. Also, thanks Jun-ichi Itaya, Philippe Bontems, Takashi Kunimoto, Takuro Yamashita and seminar participants at the 18th Meeting of the Association for Public Economic Theory Conference in Paris, the 73th Annual Congress of the International Institute of Public Finance Conference in Tokyo, Summer 
Workshop on Economic Theory 2016 at Otaru University of Commerce, and Economic Theory and Policy Workshop at Tokyo Metropolitan University. Financial support from KAKENHI (26285065) is gratefully acknowledged.

\section{References}

[1] Suits, D.B. and Musgrave, R.A. (1953) Ad Valorem and Unit Taxes Compared. The Quarterly Journal of Economics, 67, 598-604. https://doi.org/10.2307/1883604

[2] Delipalla, S. and Keen, M. (1992) The Comparison between Ad Valorem and Specific Taxation under Imperfect Competition. Journal of Public Economics, 49, 351-367. https://doi.org/10.1016/0047-2727(92)90073-O

[3] Skeath, S.E. and Trandel, G.A. (1994) A Pareto Comparison of Ad Valorem and Unit Taxes in Noncompetitive Environments. Journal of Public Economics, 53, 53-71. https://doi.org/10.1016/0047-2727(94)90013-2

[4] Myles, G.D. (1996) Imperfect Competition and the Optimal Combination of Ad Valorem and Specific Taxation. International Tax and Public Finance, 3, 29-44. https://doi.org/10.1007/BF00400145

[5] Denicoló, V. and Matteuzzi, M. (2000) Specific and Ad Valorem Taxation in Asymmetric Cournot Oligopolies. International Tax and Public Finance, 7, 335-342. https://doi.org/10.1023/A:1008709914537

[6] Anderson, S.P., de Palma, A. and Kreider, B. (2001) The Efficiency of Indirect Taxes under Imperfect Competition. Journal of Public Economics, 81, 231-251. https://doi.org/10.1016/S0047-2727(00)00085-2

[7] Aiura, H. and Ogawa, H. (2013) Unit Tax versus Ad Valorem Tax: A Tax Competition Model with Cross-Border Shopping. Journal of Public Economics, 105, 30-38. https://doi.org/10.1016/j.jpubeco.2013.06.004

[8] Kay, J.A. and Keen, M.J. (1983) How Should Commodities Be Taxed? European Economic Review, 23, 339-358. https://doi.org/10.1016/0014-2921(83)90037-5

[9] Kay, J.A. and Keen, M.J. (1991) Product Quality under Specific and Ad Valorem Taxation. Public Finance Quarterly, 19, 371-385. https://doi.org/10.1177/109114219101900207

[10] Delipalla, S. and Keen, M. (2006) Product Quality and the Optimal Structure of Commodity Taxes. Journal of Public Economic Theory, 8, 547-554. https://doi.org/10.1111/j.1467-9779.2006.00277.x

[11] Bastani, S., Blomquist, S. and Micheletto, L. (2016) Optimal Commodity Taxation with Varying Quality of Goods. Research in Economics, 70, 89-100. https://doi.org/10.1016/j.rie.2015.11.005

[12] Atkinson, A.B. and Stiglitz, J.E. (1976) The Design of Tax Structure: Direct versus Indirect Taxation. Journal of Public Economics, 6, 55-75. https://doi.org/10.1016/0047-2727(76)90041-4

[13] Houthakker, H.S. (1952) Compensated Changes in Quantities and Qualities Consumed. The Review of Economic Studies, 19, 155-164. https://doi.org/10.2307/2296018

[14] Atkinson, A.B. and Stiglitz, J.E. (1972) The Structure of Indirect Taxation and Economic Efficiency. Journal of Public Economics, 1, 97-119.

https://doi.org/10.1016/0047-2727(72)90021-7 


\section{Appendix A: Comparative Statics under Varying Tax Rates}

Under the ad-valorem tax, individuals problem is formulated as follows.

$$
\begin{aligned}
& \max _{y, \theta} v(y, \theta) \\
& \text { s.t. }\left(1+t^{a}\right) p(\theta) y \leq I .
\end{aligned}
$$

The corresponding Lagrangian is:

$$
\mathcal{L}=v(y, \theta)+\gamma^{a}\left[I-\left(1+t^{a}\right) p(\theta) y\right]
$$

The first-order conditions are given by:

$$
\begin{gathered}
\frac{\partial \mathcal{L}}{\partial y}=v_{y}-\gamma^{a}\left(1+t^{a}\right) p(\theta)=0 \\
\frac{\partial \mathcal{L}}{\partial \theta}=v_{\theta}-\gamma^{a}\left(1+t^{a}\right) p^{\prime}(\theta) y=0 \\
\frac{\partial \mathcal{L}}{\partial \gamma^{a}}=I-\left(1+t^{a}\right) p(\theta) y=0
\end{gathered}
$$

The bordered Hessian matrix for this problem is as follows.

$$
K=\left[\begin{array}{ccc}
v_{y y} & -\gamma^{a}\left(1+t^{a}\right) p^{\prime}(\theta)+v_{y \theta} & -\left(1+t^{a}\right) p(\theta) \\
-\gamma^{a}\left(1+t^{a}\right) p^{\prime}(\theta)+v_{y \theta} & v_{\theta \theta}-\gamma^{a}\left(1+t^{a}\right) p^{\prime \prime}(\theta) y & -\left(1+t^{a}\right) p^{\prime}(\theta) y \\
-\left(1+t^{a}\right) p(\theta) & -\left(1+t^{a}\right) p^{\prime}(\theta) y & 0
\end{array}\right]
$$

Its determinant $|K|$ is:

$$
|K|=2 \frac{v_{y}\left(v_{\theta}\right)^{2}}{y\left(\gamma^{a}\right)^{2}}\left(\varepsilon_{y}^{v_{\theta}}-1\right)-\left[\left(\frac{v_{y}}{\gamma^{a}}\right)^{2} v_{\theta}\left\{\frac{v_{\theta \theta}}{v_{\theta}}-\frac{p^{\prime \prime}(\theta)}{p^{\prime}(\theta)}\right\}+\left(\frac{v_{\theta}}{\gamma^{a}}\right)^{2} v_{y y}\right]
$$

Here, we assume that $\varepsilon_{y}^{v_{\theta}} \geq 1$ and $p^{\prime \prime}(\theta) \geq 0$ for utility maximization, that is, $|K|$ is positive. Therefore, it ensures the existence of the inverse matrix $K^{-1}$ and then Cramer's rule is available. Then, the derivative of $\theta$ with respect to $t^{a}$ is:

$$
\begin{aligned}
\frac{\partial \theta}{\partial t^{a}} & =\frac{1}{|K|}\left|\begin{array}{ccc}
v_{y y} & \gamma^{a} p(\theta) & -\left(1+t^{a}\right) p(\theta) \\
-\gamma^{a}\left(1+t^{a}\right) p^{\prime}(\theta)+v_{y \theta} & \gamma^{a} p^{\prime}(\theta) y & -\left(1+t^{a}\right) p^{\prime}(\theta) y \\
-\left(1+t^{a}\right) p(\theta) & p(\theta) y & 0
\end{array}\right| \\
= & \frac{1}{|K|} \frac{v_{y} v_{\theta} p(\theta)}{\gamma^{a}}\left(1-\rho-\varepsilon_{y}^{v_{\theta}}\right)
\end{aligned}
$$

Also, the derivative of $y$ can be found as follows:

$$
\begin{aligned}
\frac{\partial y}{\partial t^{a}} & =\frac{1}{|K|}\left|\begin{array}{ccc}
\gamma^{a} p(\theta) & -\gamma^{a}\left(1+t^{a}\right) p^{\prime}(\theta)+v_{y \theta} & -\left(1+t^{a}\right) p(\theta) \\
\gamma^{a} p^{\prime}(\theta) y & v_{\theta \theta}-\gamma^{a}\left(1+t^{a}\right) p^{\prime \prime}(\theta) y & -\left(1+t^{a}\right) p^{\prime}(\theta) y \\
p(\theta) y & -\left(1+t^{a}\right) p^{\prime}(\theta) y & 0
\end{array}\right| \\
& =\frac{1}{|K|} \frac{v_{\theta} p(\theta) y}{\gamma^{a}}\left(\frac{v_{\theta}}{y}\left(1-\varepsilon_{y}^{v_{\theta}}\right)+v_{y}\left\{\frac{v_{\theta \theta}}{v_{\theta}}-\frac{p^{\prime \prime}(\theta)}{p^{\prime}(\theta)}\right\}\right)
\end{aligned}
$$


On the other hand, individuals' problem under the specific tax is:

$$
\begin{aligned}
& \max _{y, \theta} v(y, \theta) \\
& \text { s.t. }\left(p(\theta)+t^{s}\right) y \leq I .
\end{aligned}
$$

The corresponding Lagrangian is:

$$
\mathcal{L}=v(y, \theta)+\gamma^{s}\left[I-\left(p(\theta)+t^{s}\right) y\right]
$$

The first-order conditions are given by:

$$
\begin{gathered}
\frac{\partial \mathcal{L}}{\partial y}=v_{y}-\gamma^{s}\left(p(\theta)+t^{s}\right)=0 \\
\frac{\partial \mathcal{L}}{\partial \theta}=v_{\theta}-\gamma^{s} p^{\prime}(\theta) y=0 \\
\frac{\partial \mathcal{L}}{\partial \gamma}=I-\left(p(\theta)+t^{s}\right) y=0
\end{gathered}
$$

The bordered Hessian matrix for this problem is:

$$
M=\left[\begin{array}{ccc}
v_{y y} & -\gamma^{s} p^{\prime}(\theta)+v_{y \theta} & -\left(p(\theta)+t^{s}\right) \\
-\gamma^{s} p^{\prime}(\theta)+v_{y \theta} & v_{\theta \theta}-\gamma^{s} p^{\prime \prime}(\theta) y & -p^{\prime}(\theta) y \\
-\left(p(\theta)+t^{s}\right) & -p^{\prime}(\theta) y & 0
\end{array}\right]
$$

Its determinant $|M|$ is:

$$
|M|=2 \frac{v_{y}\left(v_{\theta}\right)^{2}}{y\left(\gamma^{s}\right)^{2}}\left(\varepsilon_{y}^{v_{\theta}}-1\right)-\left[\left(\frac{v_{y}}{\gamma^{s}}\right)^{2} v_{\theta}\left\{\frac{v_{\theta \theta}}{v_{\theta}}-\frac{p^{\prime \prime}(\theta)}{p^{\prime}(\theta)}\right\}+\left(\frac{v_{\theta}}{\gamma^{s}}\right)^{2} v_{y y}\right]
$$

Again, we assume that $\varepsilon_{y}^{v_{\theta}} \geq 1$ and $p^{\prime \prime}(\theta) \geq 0$ for utility maximization, that is, $|M|$ is positive. Using Cramer's rule

$$
\begin{aligned}
\frac{\partial \theta}{\partial t^{s}} & =\frac{1}{|M|}\left|\begin{array}{ccc}
v_{y y} & \gamma^{s} & -\left(p(\theta)+t^{s}\right) \\
-\gamma^{s} p^{\prime}(\theta)+v_{y \theta} & 0 & -p^{\prime}(\theta) y \\
-\left(p(\theta)+t^{s}\right) & y & 0
\end{array}\right| \\
& =\frac{1}{|M|} \frac{v_{\theta} v_{y}}{\gamma^{s}}\left(2-\rho-\varepsilon_{y}^{v_{\theta}}\right)
\end{aligned}
$$

Similarly, we observe the derivative of $y$ on $t^{s}$ as follows.

$$
\begin{aligned}
\frac{\partial y}{\partial t^{s}} & =\frac{1}{|M|}\left|\begin{array}{ccc}
\gamma^{s} & -\gamma^{s} p^{\prime}(\theta)+v_{y \theta} & -\left(p(\theta)+t^{s}\right) \\
0 & v_{\theta \theta}-\gamma^{s} p^{\prime \prime}(\theta) y & -p^{\prime}(\theta) y \\
y & -p^{\prime}(\theta) y & 0
\end{array}\right| \square \\
& =\frac{1}{|M|}\left(-\frac{v_{\theta} v_{\theta y} y}{\gamma^{s}}+\frac{v_{y} v_{\theta} y}{\gamma^{s}}\left(\frac{v_{\theta \theta}}{v_{\theta}}-\frac{p^{\prime \prime}(\theta)}{p^{\prime}(\theta)}\right)\right)
\end{aligned}
$$




\section{Appendix B: A Sufficient Condition for the Maximization} Problem

Assume $p(\theta)=a \theta$ and $v(y, \theta)=\left(\alpha y^{-\sigma}+\beta \theta^{-\sigma}\right)^{-\frac{1}{\sigma}}$, where $a>0, \quad \alpha>0$, $\beta>0, \alpha+\beta=1$, and $\sigma \geq 1$. In this case, $\varepsilon_{y}^{v_{\theta}}$ is given by:

$$
\varepsilon_{y}^{v_{\theta}}=\alpha(\sigma+1)\left(\alpha y^{-\sigma}+\beta \theta^{-\sigma}\right)^{-1} y^{-\sigma}
$$

Before examining the second-order conditions under ad-valorem tax and specific tax, we suggest the first-order conditions in the setting from Equation (3) and Equation (4):

$$
\begin{gathered}
\alpha y^{-\sigma}=\beta \theta^{-\sigma} \\
y^{\sigma}=\frac{\alpha}{\beta} \frac{a \theta^{\sigma+1}}{a \theta+t^{s}}
\end{gathered}
$$

Equation (B.2) is the first-order condition under ad-valorem tax and Equation (B.3) is one under specific tax.

We now turn to the analysis of the second-order conditions. First, we derive a sufficient condition under an ad-valorem tax. Substituting Equation (B.2) into Equation (B.1) yields:

$$
\varepsilon_{y}^{v_{\theta}}=\frac{1}{2}(\sigma+1)
$$

Therefore, if $\sigma \geq 1, \quad \varepsilon_{y}^{v_{\theta}} \geq 1$. On the other hand, substituting Equation (B.3) into Equation (B.1), $\varepsilon_{y}^{v_{\theta}}$ under specific tax can be rewritten as follows:

$$
\varepsilon_{y}^{v_{\theta}}=(\sigma+1) \frac{a \theta+t^{s}}{2 a \theta+t^{s}}
$$

This means that if $\sigma \geq \frac{a \theta}{a \theta+t^{s}}, \quad \varepsilon_{y}^{v_{\theta}} \geq 1$. Note that $\frac{a \theta}{a \theta+t^{s}}<1$ under $R>0$.

To sum up, $\sigma \geq 1$ is a sufficient condition to yield a locally maximum solution under both ad-valorem and specific tax.

Next, we compute $\rho$ under the setting. By the definition and Equation (B.1), it can be rewritten as follows:

$$
\rho=-(\sigma+1)\left[\alpha\left(\alpha y^{-\sigma}+\beta \theta^{-\sigma}\right)^{-1} y^{-\sigma}-1\right]=1-\varepsilon_{y}^{v_{\theta}}+\sigma
$$

Substituting Equation (B.6) into Equation (9), it yields:

$$
\frac{\partial \theta}{\partial t^{s}}=\frac{1}{|M|} \frac{v_{\theta} v_{y}}{\gamma^{s}}(1-\sigma)
$$

As a result, the sign of $\frac{\partial \theta}{\partial t^{s}}$ is determined by $\sigma$. If $\sigma$ is lower than 1 , it is positive since the substitutability is high. However, $\sigma$ is equal to or greater than 1 for utility maximization, which means that the complementarity is high. Therefore, $\frac{\partial \theta}{\partial t^{s}}$ is non-positive under $\sigma \geq 1$. 


\section{Appendix C: The Welfare Comparison}

Assume that the price function is linear and individual's preference is the CES utility function. First, we compute the optimal indirect utility function under ad-valorem tax. Substituting Equation (B.2) into Equation (1) yields:

$$
y^{a}=\sqrt{\frac{I}{\left(1+t^{a}\right) a}\left(\frac{\alpha}{\beta}\right)^{\frac{1}{\sigma}}}
$$

In addition, using Equation (B.2) and Equation (C.1), Equation (5) is rewritten as follows:

$$
t^{a}=\frac{R}{I-R}
$$

Combining Equation (C.1) and Equation (C.2) yields:

$$
y^{a}=\sqrt{\frac{I-R}{a}\left(\frac{\alpha}{\beta}\right)^{\frac{1}{\sigma}}}
$$

Thus, we can derive the optimal indirect utility function, using Equation (B.2) and then substituting Equation (C.3) into the CES utility function as follows:

$$
\begin{aligned}
v\left(y^{a}, \theta^{a}\right) & =\left(\alpha y^{-\sigma}+\beta \theta^{-\sigma}\right)^{-\frac{1}{\sigma}}=(2 \alpha)^{-\frac{1}{\sigma}} y^{a} \\
& =2^{-\frac{1}{\sigma}}(\alpha \beta)^{-\frac{1}{2 \sigma}} R^{\frac{1}{2}}\left(\frac{\frac{I}{R}-1}{a}\right)^{\frac{1}{2}}
\end{aligned}
$$

Here, we assume that $\frac{I}{R}>1$ to avoid his bankruptcy. Next, we compute the optimal indirect utility function under specific tax. From Equation (6), we can get

$$
y^{s}=\frac{R}{t^{s}}
$$

Substituting Equation (C.5) into Equation (2) yields:

$$
\theta^{s}=\frac{t^{s}\left(\frac{I}{R}-1\right)}{a}
$$

Moreover, substituting Equation (C.6) into Equation (B.3) and using Equation (C.5) yields:

$$
y^{s}=\left(\frac{\alpha}{\beta}\right)^{\frac{1}{2 \sigma}}\left[\frac{\left(\frac{I}{R}-1\right)^{\sigma+1}}{a^{\sigma} \frac{I}{R}}\right]^{\frac{1}{2 \sigma}} R^{\frac{1}{2}}
$$

On the other hand, substituting Equation (C.5) into Equation (C.6) yields:

$$
\theta^{s}=\frac{I-R}{a y^{s}}
$$


Substituting Equation (C.7) into Equation (C.8) yields:

$$
\theta^{s}=\frac{\frac{I}{R}-1}{a}\left(\frac{\alpha}{\beta}\right)^{\frac{-1}{2 \sigma}}\left[\frac{\left(\frac{I}{R}-1\right)^{\sigma+1}}{a^{\sigma} \frac{I}{R}}\right]^{\frac{-1}{2 \sigma}} R^{\frac{1}{2}}
$$

Thus, we can derive the optimal indirect utility function, substituting Equation (C.7) and Equation (C.9) into the CES utility function as follows:

$$
v\left(y^{s}, \theta^{s}\right)=(\alpha \beta)^{-\frac{1}{2 \sigma}} R^{\frac{1}{2}}\left(\frac{\frac{I}{R}-1}{a}\right)^{\frac{\sigma+1}{2 \sigma}}\left(\frac{I}{R}\right)^{\frac{-1}{2 \sigma}} a^{\frac{1}{2 \sigma}}\left(2-\frac{R}{I}\right)^{\frac{-1}{\sigma}}
$$

Now, we compare the utility level under ad-valorem tax with one under specific tax. Using Equation (C.4) and Equation (C.10), the difference is

$$
\begin{aligned}
& v\left(y^{a}, \theta^{a}\right)-v\left(y^{s}, \theta^{s}\right) \\
& =(\alpha \beta)^{-\frac{1}{2 \sigma}} R^{\frac{1}{2}}\left[2^{-\frac{1}{\sigma}}\left(\frac{\frac{I}{R}-1}{a}\right)^{\frac{1}{2}}-\left(\frac{\frac{I}{R}-1}{a}\right)^{\frac{\sigma+1}{2 \sigma}}\left(\frac{I}{R}\right)^{-\frac{1}{2 \sigma}} a^{\frac{1}{2 \sigma}}\left(2-\frac{R}{I}\right)^{\frac{-1}{\sigma}}\right] \\
& =(\alpha \beta)^{-\frac{1}{2 \sigma}} R^{\frac{1}{2}}\left(\frac{\frac{I}{R}-1}{a}\right)^{\frac{1}{2}}\left[\left(\frac{1}{2}\right)^{\frac{1}{\sigma}}-\left(\frac{\frac{I}{R}-1}{\frac{I}{R}\left(2-\frac{R}{I}\right)^{2}}\right)^{\frac{1}{2 \sigma}}\right] \\
& =(\alpha \beta)^{-\frac{1}{2 \sigma}} R^{\frac{1}{2}}\left[\frac{\frac{I}{R}-1}{a}\right)^{\frac{1}{2}}\left[\left(\frac{1}{4}\right)^{\frac{1}{2 \sigma}}-\left(\frac{\frac{I}{R}-1}{\frac{I}{R}\left(2-\frac{R}{I}\right)^{2}}\right]\right.
\end{aligned}
$$

Note that the second term in the bracket is smaller than $\left(\frac{1}{4}\right)^{\frac{1}{2 \sigma}}$. To show the fact, we define $f\left(\frac{I}{R}\right)$ as follows:

$$
f\left(\frac{I}{R}\right) \equiv \frac{I}{R}\left(2-\frac{R}{I}\right)^{2}-4\left(\frac{I}{R}-1\right)=4 \frac{R}{I}
$$

Therefore, $f\left(\frac{I}{R}\right)$ is positive. This implies that

$$
\left(\frac{1}{4}\right)^{\frac{1}{2 \sigma}}>\left(\frac{\frac{I}{R}-1}{\frac{I}{R}\left(2-\frac{R}{I}\right)^{2}}\right)^{\frac{1}{2 \sigma}}
$$


Therefore, $v\left(y^{a}, \theta^{a}\right)-v\left(y^{s}, \theta^{s}\right)$ is positive except for $\sigma=\infty$. Moreover, $v\left(y^{a}, \theta^{a}\right)-v\left(y^{s}, \theta^{s}\right)$ is close to zero as $\sigma$ goes to $\infty$ from Equation (C.11). In addition, $\frac{1}{\alpha \beta}>1$ implies that $(\alpha \beta)^{-\frac{1}{2 \sigma}}$ is decreasing in $\sigma$. With the bracket decreasing in $\sigma$, we can state that $v\left(y^{a}, \theta^{a}\right)-v\left(y^{s}, \theta^{s}\right)$ is decreasing in $\sigma$.

\section{Appendix D: General Case under Both Ad-Valorem and Specific Taxes}

Under both ad-valorem and specific taxes, individuals problem is formulated as follows.

$$
\begin{aligned}
& \max _{y, \theta} v=v(y, \theta) \\
& \text { s.t. }\left[\left(1+t^{a}\right) p(\theta)+t^{s}\right] y \leq I .
\end{aligned}
$$

The first-order conditions are given by:

$$
\begin{gathered}
\frac{\partial \mathcal{L}}{\partial y}=v_{y}-\gamma\left[\left(1+t^{a}\right) p(\theta)+t^{s}\right]=0 \\
\frac{\partial \mathcal{L}}{\partial \theta}=v_{\theta}-\gamma\left(1+t^{a}\right) p^{\prime}(\theta) y=0 \\
\frac{\partial \mathcal{L}}{\partial \gamma}=I-\left[\left(1+t^{a}\right) p(\theta)+t^{s}\right] y=0
\end{gathered}
$$

The bordered Hessian matrix for this problem is:

$$
Q=\left[\begin{array}{ccc}
v_{y y} & -\gamma\left(1+t^{a}\right) p^{\prime}(\theta)+v_{y \theta} & -\left[\left(1+t^{a}\right) p(\theta)+t^{s}\right] \\
-\gamma\left(1+t^{a}\right) p^{\prime}(\theta)+v_{y \theta} & v_{\theta \theta}-\gamma\left(1+t^{a}\right) p^{\prime \prime}(\theta) y & -\left(1+t^{a}\right) p^{\prime}(\theta) y \\
-\left[\left(1+t^{a}\right) p(\theta)+t^{s}\right] & -\left(1+t^{a}\right) p^{\prime}(\theta) y & 0
\end{array}\right]
$$

Its determinant $|Q|$ is:

$$
|Q|=2 \frac{v_{y}\left(v_{\theta}\right)^{2}}{y(\gamma)^{2}}\left(\varepsilon_{y}^{v_{\theta}}-1\right)-\left[\left(\frac{v_{y}}{\gamma}\right)^{2} v_{\theta}\left\{\frac{v_{\theta \theta}}{v_{\theta}}-\frac{p^{\prime \prime}(\theta)}{p^{\prime}(\theta)}\right\}+\left(\frac{v_{\theta}}{\gamma}\right)^{2} v_{y y}\right]
$$

Here, we assume that $\varepsilon_{y}^{v_{\theta}} \geq 1$ and $p^{\prime \prime}(\theta) \geq 0$ to ensure the maximization problem. Therefore, since inverse matrix of $Q$ exists, we can apply Cramer's rule and then obtain following results.

$$
\begin{gathered}
\frac{\partial \theta}{\partial t^{a}}-\frac{\partial \theta}{\partial t^{s}} p(\theta)=\frac{-1}{|Q|} \gamma p^{\prime}(\theta) y\left[\left(1+t^{a}\right) p(\theta)+t^{s}\right]^{2} \\
\frac{\partial y}{\partial t^{s}}-\frac{\partial y}{\partial t^{s}} p(\theta)=\frac{1}{|Q|} \gamma\left(1+t^{a}\right)\left(p^{\prime}(\theta) y\right)^{2}\left[\left(1+t^{a}\right) p(\theta)+t^{s}\right]
\end{gathered}
$$

The objective of the government is to maximize the indirect utility $V \equiv V\left(t^{s}, t^{a}\right) \equiv u\left(\theta^{*} \equiv \theta\left(t^{s}, t^{a}\right), y^{*} \equiv y\left(t^{s}, t^{a}\right)\right) \quad$ subject to the government's 
budget constraint $t^{a} p\left(\theta^{*}\right) y^{*}+t^{s} y^{*}=R$ by choosing $t^{a}$ and $t^{s}$. The first order conditions are

$$
\begin{gathered}
\frac{\partial V}{\partial t^{a}}+\lambda\left[p(\theta) y+t^{a} p^{\prime}(\theta) \frac{\partial \theta}{\partial t^{a}} y+t^{a} p(\theta) \frac{\partial y}{\partial t^{a}}+t^{s} \frac{\partial y}{\partial t^{a}}\right]=0 \\
\frac{\partial V}{\partial t^{s}}+\lambda\left[y+t^{a} p^{\prime}(\theta) \frac{\partial \theta}{\partial t^{s}} y+t^{a} p(\theta) \frac{\partial y}{\partial t^{s}}+t^{s} \frac{\partial y}{\partial t^{s}}\right]=0
\end{gathered}
$$

Using the Roy's identity, Equation (D.3) and Equation (D.4) can be rewritten as

$$
\begin{gathered}
(\lambda-\alpha) p(\theta) y+\lambda\left[t^{a} p^{\prime}(\theta) \frac{\partial \theta}{\partial t^{a}} y+t^{a} p(\theta) \frac{\partial y}{\partial t^{a}}+t^{s} \frac{\partial y}{\partial t^{a}}\right]=0 \\
(\lambda-\alpha) y+\lambda\left[t^{a} p^{\prime}(\theta) \frac{\partial \theta}{\partial t^{s}} y+t^{a} p(\theta) \frac{\partial y}{\partial t^{s}}+t^{s} \frac{\partial y}{\partial t^{s}}\right]=0
\end{gathered}
$$

where $\alpha \equiv \frac{\partial V}{\partial I}$. Combining Equation (D.5) and Equation (D.6), we can get

$$
\frac{t^{a} p\left(\theta^{*}\right)}{t^{a} p\left(\theta^{*}\right)+t^{s}}=\frac{-p\left(\theta^{*}\right)\left[\frac{\partial y}{\partial t^{s}}-\frac{\partial y}{\partial t^{s}} p(\theta)\right]}{p^{\prime}\left(\theta^{*}\right) y^{*}\left[\frac{\partial \theta}{\partial t^{a}}-\frac{\partial \theta}{\partial t^{s}} p(\theta)\right]}=\frac{\left(1+t^{a}\right) p\left(\theta^{*}\right)}{\left(1+t^{a}\right) p\left(\theta^{*}\right)+t^{s}}
$$

The second equality is derived by substituting Equation (D.1) and Equation (D.2). Note that the equality is satisfied only when $t^{s}$ is zero. This is because $\frac{\left(1+t^{a}\right) p\left(\theta^{*}\right)}{\left(1+t^{a}\right) p\left(\theta^{*}\right)+t^{s}}$ is greater than $\frac{t^{a} p\left(\theta^{*}\right)}{t^{a} p\left(\theta^{*}\right)+t^{s}}$ if $t^{s}$ is positive. Therefore, wholly ad-valorem taxation is optimal. 